ojs.uv.es/index.php/qfilologia/index

Rebut: 20.06.2020. Acceptat: 27.07.2020

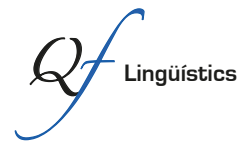

Per a citar aquest article: Gonçalves, Maria Filomena. 2020. “Gramática escolar e 'gramática popular' no último quartel do século xix: subsídios para uma historiografia do ensino da língua portuguesa”. Quaderns de Filologia: Estudis Lingüístics XXV: 29-4I.

doi: $10.7203 /$ QF.25.19066

\title{
Gramática escolar e "gramática popular" no último quartel do século XIX: subsídios para uma historiografia do ensino da língua portuguesa
}

\author{
College Grammars and Popular Grammars in the Last Quarter of the igth Century: \\ a Historiographical Aid for Teaching Portuguese
}

\author{
Maria Filomena Gonçalves \\ Universidade de Évora ${ }^{\mathrm{I}}$ \\ mfg@uevora.pt
}

Resumo: Nas últimas décadas, tem vindo a ser compulsado o "corpus fundamental" das obras gramaticais. Apesar disso, não são poucos os textos relegados para uma "historiografia menor" da gramática portuguesa. A partir de um "estado da questão" sobre a gramática escolar no último quartel do século XIX, neste artigo analisam-se duas "gramáticas populares" (I87I, I882) como textos metalinguísticos que apresentam características estruturais, conceptuais, terminológicas e discursivas sintonizadas com o objectivo de levar ao grande público um conhecimento acessível e atualizado.

Palavras chave: gramática popular; gramática escolar; português; língua materna.

Abstract: In these last decades, scholars have been examining the "fundamental corpus" of grammar publications. As a result, quite a few texts that concentrated on a "minor historiography" of the Portuguese grammar were produced. Using as a springboard a discussion on the "state of the art" on college grammars in the last quarter of the $19^{\text {th }}$ century, in this paper we pay particular attention to two "gramáticas populares" since they are metalinguistic texts with structural, conceptual, terminological, and discursive characteristics that aim at reaching a wider public, thus providing an accessible and actualized knowledge.

Keywords: college grammar; "gramática popular"; Portuguese; native language.

${ }^{\mathrm{I}}$ ECS-DLL. CIDEHUS-UÉ/FCT/ PROJETO UIDB/00057/2020. 


\section{Preâmbulo}

Neste trabalho tratar-se-á das "gramáticas populares", denominação aqui atribuída às obras que, publicadas em coleções voltadas para a vulgarização do conhecimento, se destinavam às classes sociais menos escolarizadas ou menos letradas. Dadas as suas características, a "gramática popular" inclui-se na "gramática escolar" (Gonçalves, 20I2); contudo, por se integrar num projeto editorial com objetivos próprios e por obedecer aos requisitos de uma coleção, a "gramática popular" deve ser encarada à luz do seu particular contexto de produção. Assim, o propósito deste estudo é duplo: por um lado, trazer para o âmbito historiográfico algumas gramáticas desse género, pois nem todas constam do repertório da tradição gramatical (Cardoso, I994) ou são mencionadas nos estudos da gramaticografia de Oitocentos (Santos, 20Io); por outro lado, contextualizar essas obras em função das coleções em que se incluem e da produção escolar daquele período.

\section{O contexto de produção das gramáticas populares}

Nas últimas décadas do século xIx registou-se, em Portugal, um movimento editorial que, além de responder a um mercado do livro em expansão, visava promover o acesso das classes menos letradas à instrução básica, à cultura e à ciência, contribuindo não só para alterar as estatísticas do analfabetismo no país - cerca da $90 \%$ da população era analfabeta nos inícios do século - mas também para a circulação, vulgarização e democratização do conhecimento (humanístico, científico e técnico) que até então, devido a fatores sociais, económicos, culturais e educativos, apenas eram acessíveis a uma elite intelectual ou a pessoas instruídas, tanto mais que a maioria dos portugueses não tinha domínio das operações básicas da literacia - ler, escrever e contar (Boto, 20I2).

Graças às reformas liberais do ensino e à liberdade de expressão, por um lado, e, por outro, às ideias positivistas, no mesmo período ganha impulso o movimento de vulgarização cultural e de "propaganda da educação" (Ribeiro, I999: I90-I9I), que irá plasmar-se em iniciativas como a criação de bibliotecas populares, a partir de I870, e o aparecimento de publicações para instruir "todas as classes" e "todas as intelligencias" (Gramm. Port., I87I). Este processo, que na verdade se vinha desenhando desde os meados do século xIX, será mais evidente no último quartel da centúria, altura em que editores, livreiros e intelectuais abraçaram a causa da instrução popular como meio para "modernizar a sociedade portuguesa, a partir de dentro, para construir uma civilização burguesa, erguer um povo de cidadãos" (Domingos, I985: 15). Para cativar as 
franjas menos escolarizadas da sociedade de então, surgem coleções populares, em pequeno formato, de fácil leitura, com livros mais baratos (50 ou ioo reais) e repertórios temáticos abrangentes e atrativos: a Bibliotheca Popular e a Bibliotheca do Povo e das Escolas ${ }^{2}$. Dado o diversificado espectro de conhecimentos literários, técnicos, científicos e práticos compilados nestas coleções populares, que as torna fontes imprescindíveis para a história da divulgação da ciência e da cultura em Portugal, é surpreendente que a inclusão de gramáticas nas referidas coleções não tenha ainda merecido a atenção dos historiógrafos da gramática portuguesa.

\section{A Grammatica Portugueza nas coleções populares}
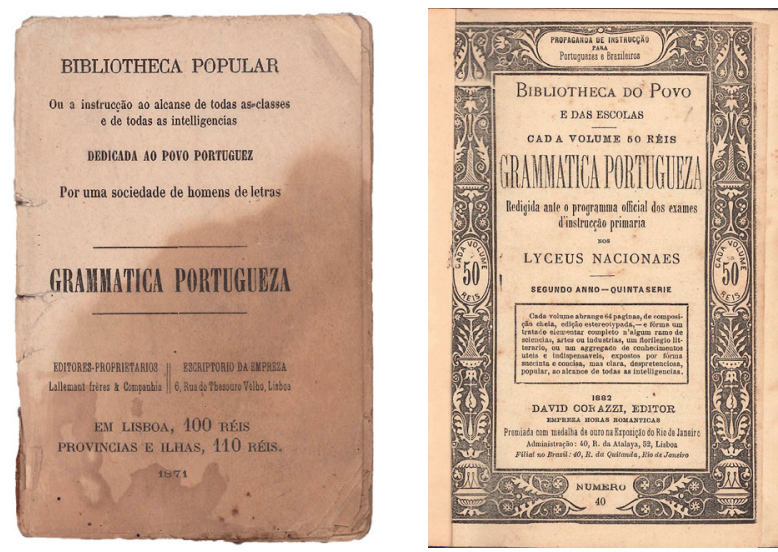

Imagem I. Portadas das gramáticas

Publicada em I87i, a gramática da Bibliotheca Popular é um opúsculo com I72 páginas, extensão superior à da Bibliotheca do Povo e das Escolas, que veio a lume onze anos depois (Gramm. Port., I882). Sem prólogo ou nota prévia dedicada ao leitor, ao contrário da obra de I882, a de I87i também não apresenta notas de rodapé que aduzam complementos informativos.

No entanto, a Grammatica portugueza (I87I) contempla uma componente prática (aspeto comum às duas obras) que consiste em fornecer modelos de

\footnotetext{
${ }^{2} \mathrm{Na}$ esteira de projetos desenvolvidos em outros países (Inglaterra, França, Itália, Estados Unidos), o editor David Corazzi (I845-I896) criou esta coleção. Em 20I9, Bonifácio (2019: 314) mostrou que a Biblioteca del Popolo, publicada em Milão desde I875, serviu de modelo a Corazzi, cuja coleção é o "nosso primeiro episódio de livro popular de massas" (Domingos, i985: 76).
} 
"analyse grammatical" e "analyse logica" (Gramm. Port., I87I: I05-I09), e trechos autorizados (i. e. literários) para servirem de "exercícios grammaticaes"3.

Quanto ao conteúdo, o caráter elementar da obra revela-se, desde logo, no índice das matérias, reproduzido no quadro abaixo.

\begin{tabular}{|c|c|c|}
\hline Introducção & & \\
\hline Primeira Parte - Etymologia & $\begin{array}{l}\text { Cap. I } \\
\text { Cap. II } \\
\text { Cap. III }\end{array}$ & $\begin{array}{l}\text { - Dos nomes e adjectivos - Do nome } \\
\text { - Formação do plural dos nomes } \\
\text { - Do adjectivo } \\
\text { - Gráus de qualificação dos adjectivos } \\
\text { - Do artigo } \\
\text { - Do pronome } \\
\text { - Do verbo [...] } \\
\text { - Da preposição } \\
\text { - Do adverbio } \\
\text { - Da conjuncção } \\
\text { - Da interjeição }\end{array}$ \\
\hline Segunda Parte - Syntaxe & $\begin{array}{l}\text { Da oraçãa } \\
\text { Cap. I } \\
\text { Cap. II } \\
\text { Cap. III } \\
\text { Cap. IV }\end{array}$ & $\begin{array}{l}\text { - Syntaxe de concordancia } \\
\text { - Syntaxe de regencia - Dos complementos } \\
\text { - Additamentos ás preposições } \\
\text { - Da syntaxe regular das orações } \\
\text { - Do periodo } \\
\text { - Da construcção das palavras e orações } \\
\text { - Das figuras } \\
\text { - Da Syntaxe figurada } \\
\text { - Dos vicios da oração } \\
\text { - Analyse grammatical } \\
\text { - Analyse logica } \\
\text { - Modelo de analyse }\end{array}$ \\
\hline Terceira Parte - Prosodia & & $\begin{array}{l}\text { - Da pronuncia } \\
\text { - Da accentuação } \\
\text { - Da quantidade }\end{array}$ \\
\hline Quarta Parte - Orthographia & $\begin{array}{l}\text { Cap. I } \\
\text { Cap. II }\end{array}$ & $\begin{array}{l}\text { - Da escripturação das palavras } \\
\text { - Vogaes e dipthongos } \\
\text { - Das consoantes } \\
\text { - Consoantes dobradas } \\
\text { - Uso das letras maiusculas } \\
\text { - Da pontuação } \\
\text { - Modo de usar a pontuação } \\
\text { - Da metrificação portugueza } \\
\text { - Varias especies de versos } \\
\text { - Varios trechos da lingoa portugueza }\end{array}$ \\
\hline
\end{tabular}

Quadro I. Matérias contidas na Grammatica Portugueza (I87I)

${ }^{3}$ Por razões de espaço, neste trabalho não se analisam nem os exercícios, nem os trechos autorizados. 
Tanto a terminologia como o tratamento das matérias denotam a filiação conservadora desta gramática, num período em que A Lingua portugueza. Phonologia, Morphologia, Syntaxe (1868), obra pioneira em que F. Adolfo Coelho já abrira caminho, em Portugal, para o método histórico-comparativo (Gonçalves, 2004), e em que o novo paradigma começara a moldar a gramática escolar (Dias, I870; Gonçalves, 20I3). A estrutura quadripartida - "Etymologia, Syntaxe, Prosodia, Orthographia" - (Gramm. Port., I87i: 5) traduz essa linha conservadora. Não existindo uma nota introdutória que aponte pressupostos ou fontes, a linhagem doutrinal pode ser deduzida a partir dos termos e sua definição, conforme se vê no quadro a seguir.

\begin{tabular}{|l|l|}
\hline \multicolumn{2}{|l|}{ Grammatica portugueza da Bibliotheca Popular } \\
\hline Grammatica & $\begin{array}{l}\text { é a disciplina que ensina a fallar e a escrever correctamente a Lin- } \\
\text { gua portugueza. }\end{array}$ \\
\cline { 2 - 3 } & $\begin{array}{l}\text { A Grammatica divide-se em geral e particular. Em geral trata dos } \\
\text { principios geraes e communs a todas as linguas; em particular } \\
\text { ensina a fallar e escrever correctamente uma só lingua. }\end{array}$ \\
\hline Etymologia & $\begin{array}{l}\text { ensina analyticamente a origem e as diversas classes de palavras } \\
\text { que constituem uma lingua. }\end{array}$ \\
\hline Syntaxe & $\begin{array}{l}\text { trata da construcção das palavras com as quaes se compõem as } \\
\text { orações, os periodos e o discurso. }\end{array}$ \\
\hline Prosodia & $\begin{array}{l}\text { ensina a accentuação das syllabas, e a conhecer e distinguir os sons } \\
\text { fundamentaes das palavras, para bem as pronunciar. }\end{array}$ \\
\hline Orthographia & $\begin{array}{l}\text { estabelece as regras para escrever correctamente as palavras, e } \\
\text { para usar convenientemente da pontuação. }\end{array}$ \\
\hline Linguagem & $\begin{array}{l}\text { é o modo porque manifestamos os pensamentos por meio de pa- } \\
\text { lavras. }\end{array}$ \\
\hline Lingua ou idioma & $\begin{array}{l}\text { é a reunião de palavras e phrases que formam a linguagem de uma } \\
\text { nação. }\end{array}$ \\
\hline Palavra & \begin{tabular}{l} 
É a combinação de sons articulados da voz humana. \\
\hline
\end{tabular}
\end{tabular}

Quadro 2. Termos e definições na Grammatica Portugueza (I87I)

Ao distinguir uma "gramática geral" de uma "gramática particular", o anónimo autor do opúsculo enraíza a doutrina na chamada gramática racionalista, entre nós conhecida como "filosófica", porquanto aqueles conceitos se ancoram no logicismo de Port-Royal (século xvir) e nos desenvolvimentos que a teoria linguística subjacente à gramática geral conheceu no século seguinte (veja-se Beauzée, I767). Contudo, nos inícios do século 
Xviı, antes da gramática de Port-Royal, o português Amaro de Roboredo (I6I9, I623) tinha proposto um método universal que representava uma renovação do ideário linguístico subjacente à didática das línguas. Se as noções introdutórias já denunciavam a esteira filosófica em que a pequena Grammatica Portugueza (I87I) se situava, essa filiação filosófica ainda é mais notória nos capítulos consagrados à "syntaxe de regencia" e à "Construcção das palavras e orações” (Gramm. Port., ı87ı: 77-94), em particular quando trata dos complementos ${ }^{4}$, porquanto a teoria sintática em torno da frase se elabora e se instrumentaliza, como é bem sabido, ao longo do século xviıi (Chevalier, I979, [1968]2006; Séguin, I993).

A Grammatica Portugueza (I882) saiu no volume 40 da Bibliotheca do Povo e das Escolas e foi elaborada por Xavier da Cunha5 (I840-I920), que dirigia a coleção. Foi pensada para um público concreto - os alunos que, concluído o ensino primário, iriam fazer exame de admissão aos liceus e, por isso, na portada se anuncia que a obra segue as "instrucções regulamentares, aprovadas pela Portaria de 9 de março de 1872 para os exames de admissão nos Lyceus Nacionaes". É de realçar que o programa do exame incluía matérias que iam do simples conceito de gramática, em linha com a tradição, até a elementos de morfologia e sintaxe, mas também de semântica e estilística (incluídas na "syntaxe figurada"). O programa abrangia, pois, conteúdos de vários âmbitos da tradição gramatical, embora conferisse certa autonomia a aspetos que anteriormente cabiam na sintaxe, como é o caso do ponto concernente ao "sentido: explicação das palavras e frases", assunto tratado, contudo, na chamada "analyse". Assim, o Programa de $1872^{6}$ é manifestamente conservador, visto incluir termos/

\footnotetext{
${ }^{4}$ Nos complementos definidos na Grammatica Portugueza (I871: 77-78, 95-96) segue Barbosa ("complementos objectivos, terminativos, restrictivos e circumstanciaes", Barbosa, I822: 395-396). Quanto à classificação das orações ("principais" e "não principais") distancia-se daquele gramático: por um lado, refere as copulativas, disjuntivas, adversativas, conclusivas, explicativas, comparativas, correlativas; por outro, as condicionais, causais, concessivas e circunstanciais e, ainda, as incidentes e integrantes.

5 Médico por formação, foi também escritor, poeta, bibliógrafo e diretor da Biblioteca Nacional (Aranha, I9II: 3I-49).

6 Compreendia os seguintes pontos: "I. Definição de grammatica; II. Palavras. Decomposição das palavras. Palavras variaveis e invariaveis; III. Palavras variaveis, I ${ }^{\circ}$ Substantivo: proprio, comum e collectivo, $2^{\circ}$ Pronome, $3^{\circ}$ Adjectivo: qualitativo e determinativo. Numero, género e graus de comparação, $4^{\circ}$ Verbo transitivo e intransitivo; regular e irregular, a) Conjugações dos verbos regulares, b) Conjugações dos verbos - ser. Ter, haver, estar, dizer, fazer, poder, pôr, saber, trazer, valer, ir, vir; IV. Palavras invariaveis. Conhecimento práctico das preposições, conjunções, advérbios e interjeições.; V. Discurso, período, e oração, a)
} 
conceitos ("analyse", "sintaxe regular", "atributo") que se vinculam ao modelo genericamente denominado como "gramática filosófica”, a qual assume, no século xix, uma feição "ideológica” (idéologie)7.

Por outro lado, o autor do opúsculo declara que o programa foi

ampliado e consideravelmente mais desenvolvido em pontos de capital importancia afim de poder tambem ser proveitosamente consultado pelos alunos que nos Lyceus Nacionaes frequentam o curso de Lingua Portuguesa (Gramm. Port., I882: Advertencia).

O subtítulo da gramática ("redigida ante o programma oficial dos exames d'instrucção primaria") confirma esta "Advertência”, inscrevendo os conteúdos gramaticais no quadro institucional vigente ${ }^{8}$, muito embora depois se note o descompasso entre o modelo praticado e aquele que presidira à Portaria de I872. Na "prevenção opportuna" com que abre a gramática propriamente dita, o autor enuncia um corte entre a metodologia adotada e a geralmente praticada nas escolas, já que estas privilegiavam a memorização de "definições para inconscientemente decorar" (Gramm. Port., I882: I). Para alterar essa prática, o conteúdo do opúsculo deveria ser "meditado e intendido, - nunca para ser materialmente decorado" 9 Se a "advertência opportuna" prevenia o leitor a respeito do método, nos "Prolegómenos" são apontadas discrepâncias entre as gramáticas daquela

Oração absoluta e orações complementares,b) Elementos da oração: sujeito, verbo, atributo e complementos; VI. Syntaxe regular. Regras principaes de concordancia do sujeito com o verbo, do adjectivo com o substantivo; VII. Analyse, a) Do sentido: explicação das palavras e frase, b) Da Syntaxe, c) Orações absolutas e complementares, d) Elementos da oração: sujeito, verbo, attributo e complementos; VIII. Syntaxe figurada - ellipse e syllepse; IX. Vicios de linguagem" (Dias, I882: I).

7 Cunhado por Destutt de Tracy (I754-I836), o termo "ideologia” colocava a gramática sob a alçada da lógica ou teoria do pensamento.

${ }^{8} \mathrm{O}$ quadro legal para o ensino constava no decreto de 22 de outubro de i870, no qual, entre outras disposições, se previa a reforma dos liceus, criados em I836 por Passos Manuel.

${ }^{9}$ Veja-a a crítica a esse método: "systema pedagogico infelizmente vulgarizado em grande numero das nossas aulas de instrucção primaria, systema que parece exclusivamente fundado no desejo de tornar idiotas os educandos (estafando-lhes a memoria com o improbo decorar dos compêndios) ou na mira de arvorar igualmente censurável de arvorar em pedantes aquelles cuja intellectualidade mais robusta saiba resistir a tão inquisitorial tormento, outro é o lemma da Bibliotheca do Povo e das Escolas. Quem d'elle não gostar, passe adeante" (Gramm. Port., I882: I-2). 
época ${ }^{\mathrm{Io}}$. As definiç̧̃̃es expostas nos Prolegómenos revelam as perspetivas confrontadas por Cunha (cf. quadro abaixo).

Grammatica conjunto de leis e preceitos, a que practicamente deve obedecer quem se propõe falar ou escrever bem em erros.

Grammatica comparada ou philosophica - Atendendo a que só pela comparação dos elementos comuns ás diversas línguas poderemos estabelecer e unificar os princípios geraes a que todas obedeçam, - conclusão, a que não será licito chegar senão pela sabia aplicação de processos philosophicos, com cujo auxilio, abstrahindo do que é individualmente peculiar em cada idioma, se averiguem apenas os meios geraes de que todos os povos têem lançado mão e feito uso, já para exprimir por palavras seu pensamento, já para graficamente pintál-o.

Grammatica geral se denomina quando apenas trata dos princípios fundamentaes, comuns a todos os idiomas.

Grammatica particular ocupa-se apenas de nos dar a conhecer as leis, preceitos e idiotismos de uma língua em especial.

Grammatica portugueza - Disciplina que ensina a falar e a escrever correctamente a lingua portugueza.

Quadro 3. Definições na Grammatica portugueza (I882)

Quanto à organização interna da gramática, ainda que sem remeter para obras concretas, o autor traça uma panorâmica dos principais sistemas adotados em gramáticas coetâneas da sua.

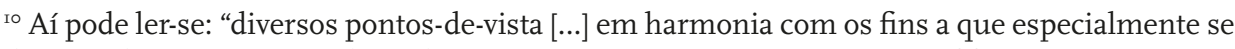
destina, dentro sempre todavia do seu campo privativo" (Gramm. Port., I882: 4).
} 


\begin{tabular}{|c|c|c|}
\hline Sistema 1 & Sistema 2 & Sistema 3 \\
\hline & & $\begin{array}{l}\text { (auctores moderníssimos, e sem duvida mais } \\
\text { filosoficamente inspirados, mais scientifica- } \\
\text { mente dirigidos...) Augusto Ep. da Silva Dias, } \\
\text { Adolfo Coelho }\end{array}$ \\
\hline $\begin{array}{l}\text { - Orthologia (maneira de } \\
\text { bem falar) } \\
\text {-lexicologia (o exame } \\
\text { isolado de cada palavra) } \\
\\
\text {-syntaxe (o exame das } \\
\text { leis por que têem de } \\
\text { governar as palavras no } \\
\text { seu conjuncto para ex- } \\
\text { primirem juízos e forma- } \\
\text { rem proposições) } \\
\text { - Orthographia (maneira } \\
\text { de bem escrever) }\end{array}$ & $\begin{array}{l}\text { Prosodia ou } \\
\text { orthoepia } \\
\text { Orthographia }\end{array}$ & $\begin{array}{l}\text { Augusto Ep. da Silva Dias: } \\
\text { - Fonologia (tratado dos sons) ou phonetica } \\
\text { - Morphologia" (tratado das formas, - que } \\
\text { estuda e classifica as diversas partes da ora- } \\
\text { ção, investiga as flexões ou accidentes das } \\
\text { palavras, e procura na etymologia a formação } \\
\text { e derivação das palavras). } \\
\text { - Syntaxe (a parte em que se estuda a manei- } \\
\text { ra de combinar entre si as diversas palavras } \\
\text { para a correcta expressão das idéas e cabal } \\
\text { enunciação dos juizos). } \\
\text { Adolfo Coelho (1881): fonologia, morfolo- } \\
\text { gia, sintaxe e semiologia. "Essa parte tem } \\
\text { que determinar as leis geraes que preside á } \\
\text { transformação da significação das palavras } \\
\text { (Coelho, 1881). }\end{array}$ \\
\hline
\end{tabular}

Quadro 4. Partes de gramática: sistemas

Apesar de o "sistema 2", tradicional, ser frequente em obras didáticas, o autor opta pela "divisão estabelecida pelo sr. Epiphanio Dias" (sistema 3) - Phonologia, Morphologia e Syntaxe -, por se lhe afigurar como "a mais plausível” para uma gramática popular. Este modelo não se traduz, contudo, na economia interna da gramática, uma vez que a sintaxe ocupa apenas 3 das 64 páginas da obra. Por outro lado, o autor anuncia um desenvolvimento especial de certas matérias, mas este nota-se apenas na morfologia, já que a obra devia contemplar os pontos do programa do exame. Embora adote o modelo de Epifânio (possivelmente a $3^{\mathrm{a}}$ ed. da Grammatica práctica, I880), o autor da Grammatica Portugueza remete para a Grammatica Philosophica (Barbosa, $\mathrm{I} 822)^{\mathrm{I2}}$, atestando, portanto, uma receção híbrida, numa espécie de enxerto de terminologia nova em doutrina velha que, na verdade, faz parte das continuidades e descontinuidades inerentes a qualquer tradição gramatical.

\footnotetext{
${ }^{\text {II }}$ Ao tratar da morfologia, o autor refere-se também à “Etymologia”, a cujo propósito menciona a gramática de Soares Barbosa (I822).

${ }^{12}$ Foi publicada postumamente com a chancela da Academia Real das Ciências de Lisboa, da qual o autor era sócio. Teve edições até i88I, altura em que o método "científico" (Gonçalves, 20I3) substituíra, no resto da Europa, a abordagem logicista da linguagem e das línguas.
} 
O cotejo textual ilustra bem a relação entre a Grammatica da Biblioteca do Povo e das Escolas e a de Epifânio da Silva Dias, embora a conexão seja assistemática, consoante ilustram os exemplos abaixo.

\begin{tabular}{|l|l|}
\hline $\begin{array}{c}\text { A. Epifânio da Silva Dias ([1870] 1880) - } \\
\text { «Grammatica práctica» }\end{array}$ & $\begin{array}{c}\text { «Grammatica Portugueza (1882) da Biblioteca } \\
\text { do Povo e das» Escolas }\end{array}$ \\
\hline $\begin{array}{l}\text { Os sons elementares da lingoa portugueza } \\
\begin{array}{l}\text { Ha monosyllabos que, em certos casos, se } \\
\text { pronuncião subordinados ao acento tóni- } \\
\text { co de uma palavra precedente, v.g. entre- } \\
\text { gavão-se-nos. As palavras que se pronun- } \\
\text { cião d'este modo, chamão-se enclíticas. }\end{array}\end{array}$ & $\begin{array}{l}\text { Os...) acontece [...] ás vezes, agremiarem-se dois } \\
\text { monosyllabos, subordinados na pronuncia ao vo- } \\
\text { cabulo que imediatamente os precede, como se } \\
\text { realmente as três não tendessem a formar mais } \\
\text { do que uma simples palavras (...). } \\
\text { Encliticas se chamam as palavras quando por } \\
\text { esta fórma se pronunciam (Fixavam-se-me; pren- } \\
\text { deram-se-lhe; estreitam-se-lhes; alargam-se-nos). }\end{array}$ \\
\hline $\begin{array}{l}\text { As palavras, segundo a sua natureza e } \\
\text { o modo como exprimem as ideias, divi- } \\
\text { dem-se em classes, chamadas partes da } \\
\text { oração ou partes do discurso. }\end{array}$ & $\begin{array}{l}\text { (...) em relação á sua natureza e papel que desim- } \\
\text { penham na linguagem, as palavras classificam-se } \\
\text { em diversos grupos ou categorias a que se dá o } \\
\text { nome de partes do discurso ou partes da oração. }\end{array}$ \\
\hline $\begin{array}{l}\text { Substantivos próprios - que dão a co- } \\
\text { nhecer individualmente as pessoas e as } \\
\text { cousas. }\end{array}$ & $\begin{array}{l}\text { Substantivos proprios dizem-se os que indivi- } \\
\text { dualmente servem para nomear uma certa pes- } \\
\text { soa ou uma certa coisa. }\end{array}$ \\
\hline $\begin{array}{l}\text { Chamão-se pronomes pessoais os prono- } \\
\text { mes que designam as pessoas que repre- } \\
\text { sentão no discurso. }\end{array}$ & $\begin{array}{l}\text { Chamam-se pronomes pessoaes os que indicam } \\
\text { (...) as pessoas que gramaticalmente se conside- } \\
\text { ram podendo figurar no discurso. }\end{array}$ \\
\hline
\end{tabular}

Quadro 5. Gramática de Silva Dias e Grammatica Portugueza (I882) - cotejo

Para lá de questões atinentes à teoria gramatical e à metodologia didática da obra, atrás mencionadas, é de realçar o registo de aspetos do uso da língua. Veja-se, a título de exemplo, a nota relativa aos chamados particípios abundantes: o verbo aceitar tem duas formas - "aceitado" e "aceito" -, sendo que atualmente a segunda prevalece no Brasil, mas "Também se usa a fórma aceite", forma que em Portugal se sobrepôs a "aceito". Neste ponto, a observação do autor do opúsculo coincide com a de Epifânio da Silva Dias ${ }^{13}$, embora nenhum deles aponte regras para o uso das chamadas formas irregulares ("aceito" e "aceite").

\footnotetext{
${ }^{13}$ Numa observação, acrescenta Dias (I882: 67) que "Em logar de acceito acceita, diz-se tambem aceite", denotando, portanto, que esta forma participal era mais recente na língua portuguesa do que as outras duas.
} 
Para finalizar, e porque esta pequena gramática pretendia servir o povo de ambos os lados do Atlântico, sublinhe-se que esse objetivo não se traduz na explicitação de diferenças entre o Português Europeu e o Português Brasileiro, ainda que estas fossem então notórias e delas houvesse testemunhos em gramáticas portuguesas elaboradas nos inícios do século XIX, como a do já citado Soares Barbosa (I822: 5I), autor que oferece exemplos da pronúncia brasileira e da colocação dos clíticos no Brasil. No entanto, na Grammatica portugueza (I882), a aproximação ao público brasileiro que também era destinatário da obra passava tão só pela inclusão de alguns exemplos relativos ao Brasil ou a realidades próprias do seu território, donde se infere que a obra veiculava uma norma claramente eurocêntrica.

\section{Notas finais}

As duas gramáticas publicadas em coleções de pendor divulgativo correspondem a uma dimensão mal conhecida e pouco estudada da Historiografia Linguística: a popularização da gramática ao serviço da instrução das classes populares. Por esse viés, tanto a gramática da Biblioteca Popular como a da Bibliotheca do Povo e das Escolas revelam a importância da gramática como instrumento integrado num programa social e institucional. Entre os aspetos ainda mal esclarecidos, valeria a pena estudar a gramática como objeto, meio e finalidade, isto é, como produto quer das ideias e doutrinas metalinguísticas, quer do contexto, envolvendo, portanto, fatores de vária ordem (tipo de escola, nível escolar, público-alvo, programas de ensino, por exemplo), elementos que, obviamente, não são irrelevantes numa Historiografia holística, por assim dizer, da gramática portuguesa e, por extensão, do ensino do português. Por outro lado, obras como a gramática da Biblioteca do Povo e das Escolas trazem à tona a concorrência entre modelos de descrição gramatical, comprovando a coexistência desses modelos na mesma obra.

A publicação de gramáticas em coleções de propaganda educativa, a preços acessíveis, visando a instrução das massas e a democratização do acesso à cultura, constitui, sem dúvida, um marco na história da gramaticografia portuguesa e, nessa perspetiva, não são obras "menores". Contudo, tal como as gramáticas "maiores", estas refletem a situação educativa do país, proporcionando elementos não só para a análise das continuidades e das ruturas na tradição gramatical, mas também para o conhecimento dos circuitos de difusão das novidades linguísticas. Daqui se infere que a gramática, entendida 
como instrumento de explicitação/classificação das unidades da língua e da sua organização, deve ser estudada do ponto de vista intra e extragramatical.

No caso das gramáticas portuguesas publicadas em coleções populares, tanto ou mais que o conteúdo (i. e. conceitos, terminologia, classificações e exemplificação), o que as singulariza é o contexto de produção e a sua função social. Conquanto os elementos aqui aduzidos não visem esgotar a análise conteudística das duas obras em apreço, é claro que, atendendo ao ambiente sócio-cultural em que surgiram e às matérias nelas expostas, ambas são pertinentes na história da gramática portuguesa e, especificamente, numa história social e institucional da gramática, capítulo até agora descurado na Historiografia da Língua Portuguesa e para o qual se procurou contribuir.

\section{Bibliografia}

Anónimo. I87i. Grammatica portugueza. Bibliotheca Popular. Lisboa: Editores-Proprietarios Lallemant Frères \& Companhia.

Anónimo. 1882. Grammatica portugueza redigida ante o programma oficial dos exames d'instrucção primaria nos Lyceus Nacionaes. Bibliotheca do Povo e das Escolas, Segundo Anno - Quinta Serie, $n^{\circ}$ 40. Lisboa/Rio de Janeiro: David CorazziEditor.

Aranha, Brito. I9II. Diccionario Bibliographico Portuguez. Estudos de Innocencio Francisco da Silva applicaveis a Portugal e ao Brazil, continuados e ampliados por [...] em virtude de contrato celebrado com o governo portuguez Xx ( $13^{\circ}$ do Supplemento). Lisboa: Imprensa Nacional.

Barbosa, Jerónimo Soares. I822. Grammatica philosophica da lingua portugueza ou principios da grammatica geral aplicados á nossa linguagem. Lisboa: Na Typographia da Academia das Sciencias.

Beauzée, Nicolas. I767. Grammaire générale. Paris: Barbou.

Bonifácio, Victor. 20I9. Um modelo para a Bibliotheca do Povo e das Escolas. Em Andrade, Manuel Lopes \& Carrington, Maria Cristina (coords.) Do manuscrito ao livro impresso I. Coimbra/Aveiro: Imprensa da Universidade de Coimbra/ Universidade de Aveiro, 313-339. doi: https://doi.org/IO.I4I95/978-989-26I7II-4-9

Boto, Carlota. 2012. A escola primária como rito de passagem: ler, escrever contar e se comportar. Coimbra: Imprensa da Universidade de Coimbra. doi: http://dx.doi. org/I0.I4I95/978-989-26-0572-2

Cardoso, Simão (comp. e org.). I994. Historiografia gramatical (1500-1920). Série Línguas e Literaturas. Porto. Faculdade de Letras. https://ler.letras.up.pt/uploads/ ficheiros/artigo724I.pdf

Chevalier, Jean-Claude. 1979. Analyse grammaticale et analyse logique, esquisse de la naissance d'un dispositif scolaire. Langue Française 4I: 20-34. 
Chevalier, Jean-Claude. [I968] 2006. Histoire de la syntaxe. Naissance de la notion de complément dans la grammaire française (1530-1750). Paris: Honoré Champion.

Coelho, Francisco Adolfo. I868. A Lingua Portugueza. Phonologia, Etymologia, Morphologia e Syntaxe. Coimbra: Imprensa da Universidade. http://purl.pt/I4I

Dias, A. Epifânio da Silva. [I870] I880. Grammatica portugueza para uso das aulas de instrucção primaria. ( $3^{\text {a }}$ ed. revista). Porto: Livraria Universal de Magalhães \& Moniz-Editores.

Domingos, Manuela D. I985. Estudos de Sociologia da Cultura. Livros e leitores no séc. XIX. Lisboa.

Gonçalves, Maria Filomena. 2004. Notas sobre o positivismo linguístico em Portugal no século xix: "Sobre a Lingua Portugueza” (I871), de F. Adolfo Coelho. Diacrítica - Ciências da Linguagem, I8: 29-56.

Gonçalves, Maria Filomena. 20I2. Gramáticas do português na transição do século XIx para o século xx: a "gramática científica". Em Cestero Mancera, A. M.; Molina Martos, I. \& Paredes García, F. (eds.) La lengua lugar de encuentro. Actas del XVI Congreso Internacional de la Asociación de Lingüística y Filología de América Latina. Alcalá de Henares: Servicios de Publicaciones, 2570-2580. http://www. mundoalfal.org/alfal2oı /index.html\#/pdf/29oalfal.pdf

Gonçalves, Maria Filomena. 20I3. Sobre a projecção do método histórico-comparativo na gramática elementar portuguesa: a Grammatica Portugueza Elementar, fundada sobre o methodo historico-comparativo (I876). Em Casanova Herrero, Emili \& Calvo Rigual, Cesáreo (eds.) Actas del XXVI Congreso Internacional de Lingüística Y de Filología Románicas (Valencia 20I0) VII. Berlin/Boston: Walter de Gruyter, 56I-57I.

Nabo, Olímpia de Jesus de B. Mourato. 20I2. Educação e difusão da ciência em Portugal A 'Bibliotheca do Povo e das Escolas' no Contexto das Edições Populares do Século XIX (Tese de Mestrado). Portalegre: Escola Superior de Educação do Instituto Politécnico de Portalegre. https://comum.rcaap.pt/bitstream/I0400.26/8402/I/ Ol\%C3\%ADmpia\%2ode\%20Jesus\%2ode\%2oBastos\%2oMourato\%2oNabo. pdf

Roboredo, Amaro. I6ı9. Methodo grammatical para todas as linguas. Lisboa: Pedro Crasbeeck.

Roboredo, Amaro de. I623. Porta de linguas ou modo muito accomodado para as entender publicado primeiro com a tradução Espanhola. Agora acrescentada a Portuguesa com numeros interliniaes, pelos quaes possa entender sem mestre estas linguas o que as não sabe [...]. Lisboa: Pedro Crasbeeck.

Santos, Maria Helena Pessoa. 2010. As ideias linguísticas portuguesas na centúria de oitocentos, 2 vols. Série Textos Universitários de Ciências Sociais e Humanas. Lisboa: Fundação Calouste Gulbenkian / Fundação para a Ciência e a Tecnologia.

Séguin, Jean-Pierre. I993. L’invention de la phrase au XVIII ${ }^{e}$ siècle. Louvain/Paris: Peeters. 
